\title{
Factors affecting patient satisfaction with ecdemic medical care: a cross-sectional study in Nanchang, China
}

This article was published in the following Dove Press journal:

Patient Preference and Adherence

\section{Xiaojun Liu ${ }^{1,2}$ \\ Hanson Lu $^{3}$ \\ Yanan Wang' \\ Wenjie Wang' \\ Zhaoxun Hou' \\ Anran Tan ${ }^{2,4}$ \\ Zongfu Mao ${ }^{1,2}$}

'School of Health Sciences, Wuhan University, Wuhan, China; ${ }^{2}$ Global Health Institute, Wuhan University, Wuhan, China; ${ }^{3}$ University of Chicago, Chicago, IL, USA; ${ }^{4}$ Global Health Research Center, Duke Kunshan University, Kunshan, China
Correspondence: Zongfu Mao Global Health Institute, Wuhan University, No 8 South Donghu Road, Wuhan 430072, China

Tel/fax +86 2768759118

Email zfmao@whu.edu.cn
Purpose: This study aimed to determine the factors that influence patient satisfaction with ecdemic medical care.

Materials and methods: Eight hundred and forty-four face-to-face interviews were conducted between October and November 2017 in two high-profile hospitals in Nanchang, China. Patient satisfaction was divided into lowest and highest satisfaction groups according the $80 / 20$ rule. Demographic factors associated with patient satisfaction were identified by logistic regression models.

Results: Respondents' main reasons for choosing a non-local hospital were "high level of medical treatment" (581/844), "good reputation of the hospital" (533/844), and "advanced medical equipment" (417/844). The top three items that dissatisfied the ecdemic patients were "long time to wait for treatment" (553/844), "complicated formalities" (307/844), and "poor overall service attitude" (288/844). Fewer female patients (adjusted odds ratio [AOR] =1.47, 95\% confidence interval $[\mathrm{CI}]=1.03-2.11)$, patients with a family per-capita monthly income (FPMI) between 3,001 and 5,000 CNY ( $\mathrm{AOR}=1.40,95 \% \mathrm{CI}=1.01-2.17$ ), inpatients ( $\mathrm{AOR}=1.46$, 95\% CI $=1.01-2.13$ ), and more patients with an FPMI $>7,000 \mathrm{CNY}$ (AOR $=0.43,95 \%$ $\mathrm{CI}=0.20-0.92)$ were detected in the lowest satisfaction group. Fewer patients with an associate's or bachelor's degree ( $\mathrm{AOR}=2.40,95 \% \mathrm{CI}=1.37-4.20)$ and patients with an FPMI $>7,000 \mathrm{CNY}$ ( $\mathrm{AOR}=3.02,95 \% \mathrm{CI}=1.10-8.33$ ) were detected in the highest satisfaction group. Moreover, more inpatients $(\mathrm{AOR}=0.70,95 \% \mathrm{CI}=0.54-0.97)$ and those aged $46-65$ years $(\mathrm{AOR}=0.63$, $95 \% \mathrm{CI}=0.33-0.98$ ) were detected in the highest satisfaction group.

Conclusion: Findings suggested that managers of the medical facilities should note the importance of increasing their publicity through a rapidly developing media, as well as the necessity of creating a more patient-friendly medical care experience. Hospitals should also focus on the medical care experience of patients with relatively lower and higher income levels, male ecdemic patients, and ecdemic outpatients.

Keywords: patient satisfaction, ecdemic medical care, ecdemic patients, the $80 / 20$ rule

\section{Introduction}

The distribution of health resources among different areas and cities varies greatly in China. ${ }^{1-3}$ High-quality health resources are mainly allocated in megacities such as Beijing, Shanghai, Guangzhou and major provincial capitals such as Wuhan, Chengdu, and Nanjing. ${ }^{1,3}$ Therefore, facing such an uneven distribution of health resources leaves no choice but to travel to big cities in order to access high-quality health resources for residents living in areas where health resources are relatively scarce. ${ }^{4}$ These patients are termed as "ecdemic patients" in China, and this care-seeking behavior is called 
"the ecdemic medical care/treatment" in China. Since the economic reform in the 1970s, many changes have taken place in China. The disease spectrum of Chinese people and general attitudes toward health have transformed. ${ }^{5-7}$ The demand for better health services of Chinese nationals is still increasing with greatly improved living standards. ${ }^{4,8}$ Consequently, such alterations have increased the prevalence of the ecdemic medical care/treatment.

The ecdemic medical care in this article specifically refers to a patient who receives medical services in any place outside an individual's officially registered residence location. ${ }^{4}$ The recent completion of the high-speed railway and expressway network have expedited intercity travel and have made the ecdemic medical care much easier. Moreover, according to the 2017 Report on China's Migrant Population Development, 292 million residents had lived in a location away from their officially registered location of residence for more than 6 months in $2016 .{ }^{9}$ Meanwhile, the 2016 Statistical Communiqué of the People's Republic of China on National Economic and Social Development records a number of 169.34 million migrant rural workers living in Chinese urban areas. ${ }^{10}$ An evident result of this is that when those migrant rural workers seek medical treatment, they are most likely to turn to the hospitals nearby instead of the hospitals in their hometown, which is most likely their formally registered location of residence. ${ }^{4}$ Hence, there are a large number of people who have had previous experience of the ecdemic medical care in China.

The Chinese government has realized the fact that there are a large number of patients who get medical treatment away from home and that the numbers are still rising rapidly. Therefore, the Chinese government has been trying to solve this issue, including establishing a direct medical insurance payment system for the ecdemic patients, building a national network for basic health care insurance, and strengthening the cooperation among administration departments of health care in different cities. ${ }^{11-14}$ These measures had effectively lessened the medical economic burden on ecdemic patients, met the demand for the ecdemic medical care to some extent, and increased the degree of satisfaction with health care services among ecdemic patients. ${ }^{11,13,14}$

Patient satisfaction is a key measurement of the quality of medical service, as it directly assesses medical service from the perspective of patients toward health care..$^{15,16}$ The National Health Service system can affect patient satisfaction. ${ }^{17,18}$ However, as the direct provider of medical service, hospitals have the ability to promote patient satisfaction by improving the quality of medical services on their side. ${ }^{19-23}$ Government and the related policies, on the other hand, have a more limited impact on the improvement of patient satisfaction.
In response to the severity of the conflict between doctors and patients, ${ }^{24,25}$ Chinese hospitals are now attempting to provide services in all aspects using the principles for patient-centered care, which may improve their service quality and efficiency, and enhance the timeliness and rationality of their decisionmaking on health care. ${ }^{26-28}$ In this process, patients, especially the ecdemic patients, can provide valuable opinions and suggestions that are crucial toward the development of hospitals. Therefore, a large number of medical facilities have added great importance to the evaluation of patient satisfaction with their medical experience, and have conducted many routine satisfaction surveys and initiatives.

Current studies on patient satisfaction have been conducted primarily to focus on the general population or groups with certain diseases, such as cancer patients. ${ }^{15-17,19-23,25-27,29}$ Some empirical studies are conducted in developed countries, focusing on patient mobility and its influencing factors. ${ }^{30-32}$ However, few research studies have specifically targeted the ecdemic patients in China. Therefore, this study considered such a population group as its object and aimed to investigate the reasons underlying their preference for specific hospitals, to determine the causes of unsatisfactory experiences in the medical facilities, and to explore differences in satisfaction between patients with different demographic statistics. Moreover, this study can also provide references for hospitals to improve their service and for policymakers to establish or adjust relevant policies.

\section{Materials and methods Material sources}

The present survey was conducted in Nanchang - the capital city of Jiangxi province as well as being one of the megacities located in the economic belt of middle reach of Yangtze River. Nanchang is a major transportation hub connecting the prosperous coastal areas of Southeast China. Convenient transportation provides access for residents from other places to seek high-quality medical care services in Nanchang. We selected the First Affiliated Hospital of Nanchang University and Jiangxi Zhonghuan Hospital, because these two comprehensive hospitals are a good representation of the high-profile public hospitals and private hospitals in Jiangxi province, respectively. They accept the largest number of patients living outside of Nanchang city.

\section{Data collection and sampling}

According to the study design, patients (or their caregivers) from other areas who were aged $\geq 18$ years were considered to be within the inclusion criteria of survey participants. The qualified participants (non-local household registration - known 
as "hukou" in Chinese) were briefly told about our study and were asked about their willingness to participate in the study. Convenience sampling strategy was used to carry out the investigation. Between October and November 2017, trained public health graduate students collected the data by means of face-to-face interviews. Our survey was conducted from 9 AM to 4 PM each day, excluding Saturday afternoons and Sundays (the hospitals provide services only to inpatients and do not operate during these times).

\section{Questionnaire}

The questionnaire used in this study was based on the Improvement and Assessment of Patient Satisfaction Questionnaire in General Hospitals. ${ }^{29}$ There was sufficient evidence for reliability and construct validity of this questionnaire; the Cronbach's alpha coefficient of the questionnaire was 0.912 , and the Cronbach's alpha coefficients of all dimensions ranged from 0.669 to 0.801 . We also designed the basic social demographic characteristic questionnaire based on local circumstances and specific needs of this study. Participants were also asked to list their main reasons for choosing a non-local hospital and the most unsatisfactory items for the hospital that served them. The majority of the questions in the original edition used a 5-point Likert scale. It is hard to differentiate patient satisfaction, as most respondents may choose "neutral" (scored 3) if using the 5-point Likert scale. ${ }^{29}$ In the current study, we used a 9-point Likert scale, where a higher score indicated higher patient satisfaction. We also measured the internal reliability of our questionnaire, and the Cronbach's alpha coefficient was 0.902 .

\section{Sample size calculation}

The sample size for this study was determined according to the formula for the cross-sectional survey study as follows: $\mathrm{n}=\frac{\mu_{\alpha / 2}^{2} \pi(1-\pi)}{\delta^{2}},{ }^{33}$ where $\mathrm{n}$ is the sample size, $\pi$ is the overall satisfaction rate, and $\delta$ is the desired level of precision. The overall satisfaction rate was obtained from pre-survey $(n=87)$, and it was $78.67 \%$. Meanwhile, we desired a 95\% confidence level and 5\% precision; hence the sample size was calculated to be: $\mathrm{n}=\frac{1.96^{2} \times 0.7867 \times(1-0.7867)}{0.05^{2}}=257.85$, rounded to 258 . However, we got 844 valid questionnaires, which was far more than expected. Hence, there should be adequate power for analyses.

\section{Statistical analysis}

The IBM SPSS version 22.0 for Windows (IBM Corporation, Armonk, NY, USA) was used to perform all the analyses in this study. An initial descriptive analysis was first conducted. The frequencies and proportions were used to summarize the respondents' demographic characteristics, their main reasons for choosing a non-local hospital, and the most unsatisfactory items for the hospital that served them. The demographic information of the participants is summarized in Table 1. The main reasons for choosing a non-local hospital are shown in Figure 1, and their most unsatisfactory items are shown in Figure 2. Patient satisfaction was divided into lower and higher satisfaction groups according the 80/20 rule (also known as Pareto principle). ${ }^{34}$ The $80 / 20$ rule states that, for many events, roughly $80 \%$ of the effects come from $20 \%$ of the causes. We believe that these $20 \%$ of patients who gave the highest and lowest satisfaction score are the target population that the managers of hospitals should especially focus on. The population with the highest and lowest scores was selected. Then, by using binary logistic regression models, we distinguished the diverse patient satisfaction in different population subgroups. The crude odds ratios (CORs) and adjusted odds ratios (AORs) with 95\% confidence interval (CI) obtained from univariate and multivariable logistic

Table I Demographic information of the participants $(\mathrm{N}=844)$

\begin{tabular}{|c|c|c|c|}
\hline Variables & $\begin{array}{l}\text { Demographic } \\
\text { characteristics }\end{array}$ & $\mathbf{n}$ & $\%$ \\
\hline \multirow[t]{2}{*}{ Gender } & Male & 402 & 47.63 \\
\hline & Female & 442 & 52.37 \\
\hline \multirow[t]{4}{*}{ Age (years) } & $\leq 25$ & 273 & 32.35 \\
\hline & $26-45$ & 289 & 34.24 \\
\hline & $46-65$ & 215 & 25.47 \\
\hline & $>65$ & 67 & 7.94 \\
\hline \multirow[t]{4}{*}{ Education level } & $\leq$ Elementary school & 321 & 38.03 \\
\hline & Middle/high school & 204 & 24.17 \\
\hline & Associate's/bachelor's degree & 210 & 24.88 \\
\hline & $\geq$ Master's degree & 109 & $12.9 \mid$ \\
\hline \multirow[t]{4}{*}{ Marital status } & Married & 543 & 64.34 \\
\hline & Unmarried & 293 & 34.72 \\
\hline & Widowed & 7 & 0.83 \\
\hline & Other & I & 0.12 \\
\hline \multirow[t]{4}{*}{ FPMI (CHY) } & $\leq 3,000$ & 408 & 48.34 \\
\hline & $3,001-5,000$ & 322 & 38.15 \\
\hline & $5,00 I-7,000$ & 71 & 8.41 \\
\hline & $>7,000$ & 43 & 5.09 \\
\hline \multirow[t]{2}{*}{ Household registration } & City & 289 & 34.24 \\
\hline & Countryside & 555 & 65.76 \\
\hline \multirow[t]{2}{*}{ Type of patient } & Outpatient & 507 & 60.07 \\
\hline & Inpatient & 337 & 39.93 \\
\hline \multirow[t]{4}{*}{ Type of health insurance } & MIUR & 239 & 28.32 \\
\hline & NRCMI & 418 & 49.53 \\
\hline & MIUW & 145 & 17.18 \\
\hline & $\mathrm{CMI}$ & 42 & 4.98 \\
\hline Total & - & 844 & 100.00 \\
\hline
\end{tabular}

Abbreviations: FPMI, family per-capita monthly income; MIUR, medical insurance for urban residents; NRCMI, new-type rural cooperative medical insurance; MIUW, medical insurance for urban workers; CMI, commercial medical insurance. 


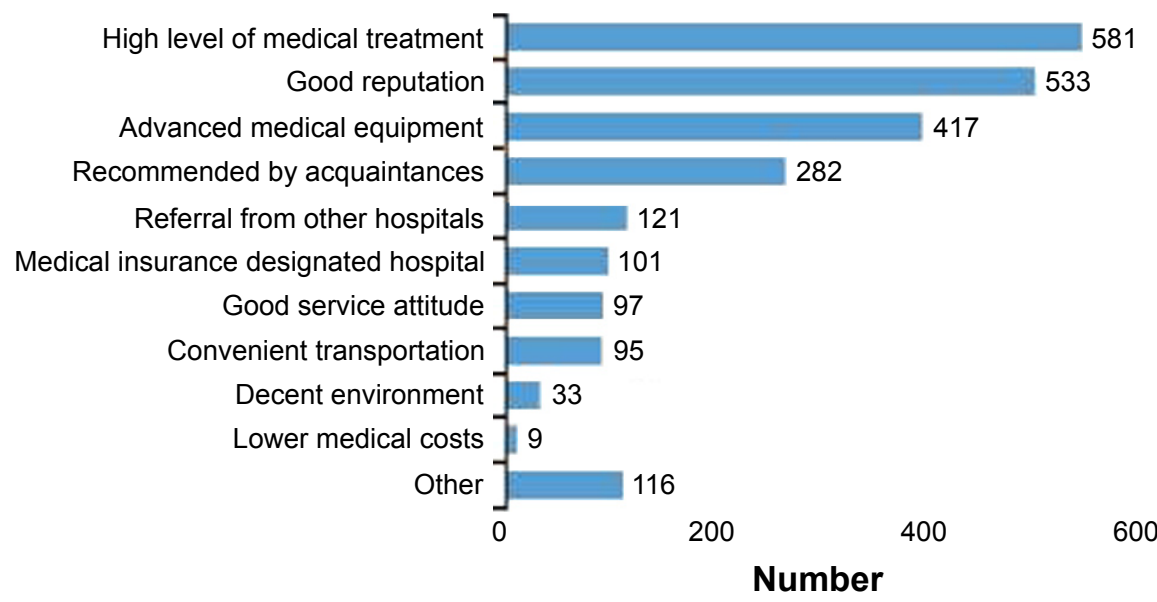

Figure I Patients' main reasons for choosing the hospital.

regression models are summarized in Tables 2 and 3, respectively. The $p$-value of $<5 \%$ was considered to be statistically significant.

\section{Quality control}

First, the questionnaire was inspected and edited by relevant domestic and international scholars and experts in this field based on the local circumstances and specific needs of this study. Second, the interviewees who carried out the investigation received strict training, and only qualified personnel were eligible for a face-to-face interview. The interviewees were very conscientious and diligent in this survey, because most of them were going to use the data for their graduation thesis. Third, pre-investigations of the target population were conducted to ensure the face validity and comprehension of the survey paper. In addition, we had a meeting every 5 days to discuss the difficulties and improvement suggestions for the interview. Finally, by using Excel 2010 (Microsoft Corporation, Redmond, WA, USA) each completed questionnaire was separately imported into two different databases by two students, and then it was cross-verified. Only the variables that were exactly the same in the two databases were considered accurate and the rest were further compared with the original questionnaire.

\section{Ethical statement}

The study protocol was reviewed and approved by the Research Ethics Board of Provincial Postgraduate Innovation Projects and School of Health Sciences of Wuhan University (IRB No YC2015-S039). Informed consent information was attached on the top of each questionnaire and presented before the surveys. The participants completed and signed the informed consent documents.

\section{Results \\ Demographic information of the participants}

A total of 844 patients participated in our study with 402 males (47.63\%) and 442 females (52.37\%), of whom most

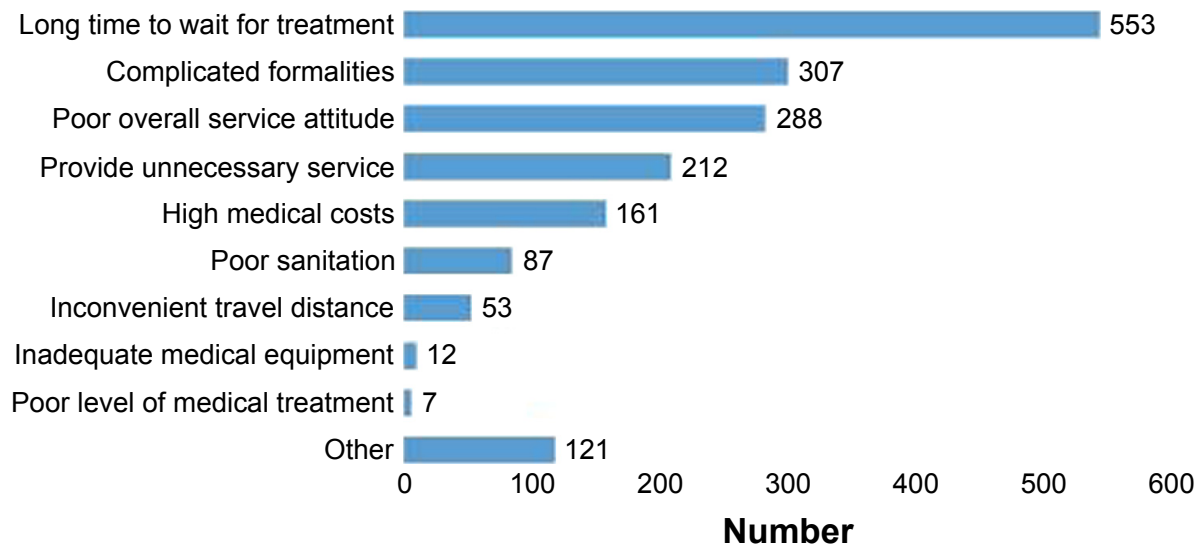

Figure 2 Patients' most unsatisfactory items regarding hospital services. 
Table 2 Logistic regression analysis of influencing factors associated with patient satisfaction (for lowest score group)

\begin{tabular}{|c|c|c|c|c|}
\hline Demographic factors & $\begin{array}{l}\text { Scored I-5 } \\
(n=170,20.14 \%)\end{array}$ & $\begin{array}{l}\text { Scored 6-9 } \\
(n=674,79.86 \%)\end{array}$ & $\begin{array}{l}\text { Crude OR } \\
(95 \% \mathrm{Cl})\end{array}$ & $\begin{array}{l}\text { Adjusted OR } \\
(95 \% \mathrm{Cl})\end{array}$ \\
\hline \multicolumn{5}{|l|}{ Gender } \\
\hline Male & 91 (22.34) & $311(77.36)$ & - & - \\
\hline Female & $79(17.87)$ & $363(82.13)$ & $1.34(0.96-1.88)$ & $1.47(1.03-2.11)^{*}$ \\
\hline \multicolumn{5}{|l|}{ Age (years) } \\
\hline$\leq 25$ & $55(20.15)$ & $218(79.85)$ & - & - \\
\hline $26-45$ & $66(22.84)$ & $223(77.16)$ & $0.85(0.57-1.28)$ & $0.79(0.42-1.49)$ \\
\hline $46-65$ & $37(17.2 \mid)$ & I 78 (82.79) & $1.21(0.77-1.93)$ & $0.99(0.46-2.10)$ \\
\hline$>65$ & $12(|7.9|)$ & 55 (82.09) & $1.16(0.58-2.31)$ & $0.96(0.38-2.40)$ \\
\hline \multicolumn{5}{|l|}{ Education level } \\
\hline$\leq$ Elementary school & $64(19.94)$ & $257(80.06)$ & - & - \\
\hline Middle/high school & $26(12.75)$ & $178(87.25)$ & $1.71(1.04-2.80)^{*}$ & $1.61(0.95-2.75)$ \\
\hline Associate's/bachelor's degree & $56(26.67)$ & $154(73.33)$ & $0.69(0.45-0.99)^{*}$ & $0.68(0.37-1.24)$ \\
\hline$\geq$ Master's degree & $24(22.02)$ & 85 (77.98) & $0.88(0.52-1.49)$ & $0.82(0.39-1.75)$ \\
\hline \multicolumn{5}{|l|}{ Marital status } \\
\hline Married & $107(19.71)$ & $436(80.29)$ & - & - \\
\hline Other & $63(20.93)$ & $238(79.07)$ & $0.93(0.65-|.3|)$ & $1.09(0.56-2.14)$ \\
\hline \multicolumn{5}{|l|}{ FPMI (CNY) } \\
\hline$\leq 3,000$ & $84(20.59)$ & $324(79.4 I)$ & - & - \\
\hline $3,00 \mathrm{I}-5,000$ & 49 (I5.22) & $273(84.78)$ & $1.44(1.01-2.13)^{*}$ & $1.40(1.01-2.17)^{*}$ \\
\hline $5,00 \mathrm{I}-7,000$ & $19(26.76)$ & $52(73.24)$ & $0.7 \mid(0.40-1.26)$ & $0.83(0.43-1.59)$ \\
\hline$>7,000$ & $18(41.86)$ & $25(58.14)$ & $0.36(0.19-0.69)^{* * *}$ & $0.43(0.20-0.92)^{* *}$ \\
\hline \multicolumn{5}{|l|}{ Household registration } \\
\hline City & $60(20.76)$ & $229(79.24)$ & - & - \\
\hline Countryside & $110(19.82)$ & $445(80.18)$ & $1.06(0.75-|.5|)$ & $0.86(0.53-1.39)$ \\
\hline \multicolumn{5}{|l|}{ Type of patient } \\
\hline Outpatient & II 3 (22.89) & 394 (77.7I) & - & - \\
\hline Inpatient & $57(16.91)$ & $280(83.09)$ & $\mathrm{I} .4 \mathrm{I}(\mathrm{I} .0 \mathrm{I}-2.0 \mathrm{I})^{*}$ & $1.46(1.01-2.13)^{*}$ \\
\hline \multicolumn{5}{|l|}{ Type of health insurance } \\
\hline MIUR & $49(20.50)$ & $190(79.50)$ & - & - \\
\hline NRCMI & $82(19.62)$ & $336(80.38)$ & $1.06(0.7|-| .57)$ & $0.99(0.57-1.72)$ \\
\hline MIUW & $33(22.76)$ & $112(77.24)$ & $0.88(0.53-1.44)$ & $0.96(0.53-1.75)$ \\
\hline CMI & $6(14.29)$ & $36(85.7 \mathrm{I})$ & $1.55(1.00-3.88)$ & $1.93(1.00-2.14)$ \\
\hline
\end{tabular}

Notes: $* p<0.05, * * p<0.01, * * * p<0.001$.

Abbreviations: FPMI, family per-capita monthly income; MIUR, medical insurance for urban residents; NRCMI, new-type rural cooperative medical insurance; MIUW, medical insurance for urban workers; CMI, commercial medical insurance; OR, odds ratio; $\mathrm{Cl}$, confidence interval.

were outpatients $(60.07 \%)$. Participants aged $\leq 25,26-45$, $46-65$, and $>65$ years accounted for $32.35 \%, 34.24 \%$, $25.47 \%$, and $7.94 \%$ of the total sample size, respectively. Most of the participants $(65.76 \%)$ were from rural areas. The participants' education level was classified as $\leq$ elementary school, middle or high school, associate's or bachelor's degree, and $\geq$ master's degree, accounting for $38.03 \%$, $24.17 \%, 24.88 \%$, and $12.91 \%$ of the total sample size, respectively. Participants' family per-capita monthly income (FPMI) <3,000 CNY (48.34\%) and 3,001-5,000 CNY $(38.15 \%)$ accounted for the majority of the sample. The largest proportion of the participants' health insurance type was new-type rural cooperative medical insurance, with $49.53 \%$ of the participants insured, followed by medical insurance for urban residents (MIUR), with $28.32 \%$ of the participants insured. The demographic information of the survey participants is summarized in Table 1.

\section{Main reasons for choosing the hospital}

Figure 1 recorded the respondents' main reasons for choosing the hospital. The top four reasons were: high level of medical treatment, good reputation of the hospital, advanced medical equipment, and recommended by acquaintances.

\section{The most unsatisfactory items for the hospital that served them}

Figure 2 records the respondents' most unsatisfactory items for the hospital that served them. The top four items were: long time to wait for treatment, complicated formalities, poor overall service attitude, and provided unnecessary service.

\section{Analysis of the demographic factors affecting patient satisfaction}

The population with the highest and lowest satisfaction was selected according to the $80 / 20$ rule. We found that $20.14 \%$ 
Table 3 Logistic regression analysis of influencing factors associated with patient satisfaction (for highest score group)

\begin{tabular}{|c|c|c|c|c|}
\hline Demographic factors & $\begin{array}{l}\text { Scored } 8-9 \\
(n=250,29.62 \%)\end{array}$ & $\begin{array}{l}\text { Scored I-7 } \\
(n=594,70.38 \%)\end{array}$ & $\begin{array}{l}\text { Crude OR } \\
(95 \% \mathrm{Cl})\end{array}$ & $\begin{array}{l}\text { Adjusted OR } \\
(95 \% \mathrm{Cl})\end{array}$ \\
\hline \multicolumn{5}{|l|}{ Gender } \\
\hline Male & $124(30.85)$ & $278(69.15)$ & - & - \\
\hline Female & $126(28.5 \mid)$ & $316(71.49)$ & $1.12(0.83-1.50)$ & $\mathrm{I} .14(0.83-1.57)$ \\
\hline \multicolumn{5}{|l|}{ Age (years) } \\
\hline$\leq 25$ & $69(25.27)$ & $204(74.73)$ & - & - \\
\hline $26-45$ & $81(28.03)$ & $208(71.97)$ & $0.87(0.60-1.26)$ & $0.78(0.44-1.43)$ \\
\hline $46-65$ & $83(38.60)$ & $132(6 \mid .40)$ & $0.54(0.37-0.79)^{* *}$ & $0.63(0.33-0.98)^{*}$ \\
\hline$>65$ & $17(25.37)$ & $50(74.63)$ & $1.00(0.54-1.84)$ & $1.37(0.60-3.11)$ \\
\hline \multicolumn{5}{|l|}{ Education level } \\
\hline$\leq$ Elementary school & $110(34.27)$ & $211(65.73)$ & - & - \\
\hline Middle/high school & $67(32.84)$ & $137(67.16)$ & $1.07(0.74-1.55)$ & $1.05(0.70-1.58)$ \\
\hline Associate's/bachelor's degree & $36(17.14)$ & $174(82.86)$ & $2.52(1.65-3.86)^{* * *}$ & $2.40(1.37-4.20)^{* *}$ \\
\hline$\geq$ Master's degree & $37(33.94)$ & $72(66.06)$ & $1.01(0.64-1.6 I)$ & $0.95(0.50-1.83)$ \\
\hline \multicolumn{5}{|l|}{ Marital status } \\
\hline Married & $170(31.31)$ & $373(68.69)$ & - & - \\
\hline Others & $80(26.58)$ & $221(73.42)$ & $1.26(0.92-1.72)$ & $0.96(0.53-1.76)$ \\
\hline \multicolumn{5}{|l|}{ FPMI (CNY) } \\
\hline$\leq 3,000$ & $136(33.33)$ & $272(66.67)$ & - & - \\
\hline $3,00 \mathrm{I}-5,000$ & $92(28.57)$ & $230(71.43)$ & $1.25(0.9 \mid-1.72)$ & $1.15(0.80-1.66)$ \\
\hline $5,00 \mathrm{I}-7,000$ & $17(23.94)$ & $54(76.06)$ & $1.59(0.89-2.84)$ & $1.22(0.64-2.33)$ \\
\hline$>7,000$ & $5(11.63)$ & $38(88.37)$ & $3.80(1.46-9.87)^{* *}$ & $3.02(1.10-8.33)^{*}$ \\
\hline \multicolumn{5}{|l|}{ Household registration } \\
\hline City & $87(30.10)$ & $202(69.90)$ & - & - \\
\hline Countryside & $163(29.37)$ & $392(70.63)$ & $\mathrm{I} .04(0.76-1.4 \mathrm{I})$ & $1.28(0.84-1.94)$ \\
\hline \multicolumn{5}{|l|}{ Type of patient } \\
\hline Outpatient & $134(26.43)$ & $373(73.57)$ & - & - \\
\hline Inpatient & $116(34.42)$ & $221(65.58)$ & $0.68(0.5 \mathrm{I}-0.92)^{* *}$ & $0.70(0.54-0.97)^{*}$ \\
\hline \multicolumn{5}{|l|}{ Type of health insurance } \\
\hline MIUR & $80(33.47)$ & $159(66.53)$ & - & - \\
\hline NRCMI & $123(29.43)$ & $295(70.57)$ & $1.21(0.86-1.70)$ & $1.57(0.96-2.56)$ \\
\hline MIUW & $37(25.52)$ & $108(74.48)$ & $1.47(0.93-2.33)$ & $1.43(0.84-2.45)$ \\
\hline CMI & $10(23.8 \mathrm{I})$ & $32(76.19)$ & $1.61(0.75-3.44)$ & $1.56(0.70-3.48)$ \\
\hline
\end{tabular}

Notes: $* p<0.05, * * p<0.01, * * * p<0.001$.

Abbreviations: FPMI, family per-capita monthly income; MIUR, medical insurance for urban residents; NRCMI, new-type rural cooperative medical insurance; MIUW, medical insurance for urban workers; CMI, commercial medical insurance; OR, odds ratio; $\mathrm{Cl}$, confidence interval.

of the respondents scored $1-5$ points (lowest satisfaction) and $29.62 \%$ scored $8-9$ points (highest satisfaction). In order to better understand the bivariate and multivariate associations of patient satisfaction versus demographic factors such as age, gender, education level, marital status, FPMI, household registration, type of patient, and type of health insurance, we obtained the CORs and AORs by implementing univariate and multivariable logistic regression models, respectively.

Analysis of the lowest score group showed that in the univariate logistic regression model, there was a higher proportion of patients with lowest satisfaction who had an associate's or bachelor's degree $(\mathrm{COR}=0.69,95 \% \mathrm{CI}=0.45-0.99)$, as compared to those with a $\leq$ elementary school educational background, and a lower proportion of patients with a middle or high school educational background (COR $=1.71,95 \%$ $\mathrm{CI}=1.04-2.80$ ). Compared to those with an FPMI $\leq 3,000 \mathrm{CNY}$, more patients with an FPMI $>7,000 \mathrm{CNY}$ were detected in the lowest satisfaction group $(\mathrm{COR}=0.36,95 \% \mathrm{CI}=0.19-0.69)$. Besides, a lower proportion of inpatients $(\mathrm{COR}=1.41,95 \%$ $\mathrm{CI}=1.01-2.01)$ was also found in the lowest satisfaction group. Multivariable logistic regression model reported that a lower proportion of female patients $(\mathrm{AOR}=1.47$, 95\% CI $=1.03-2.11$ ), patients with an FPMI between 3,001 and 5,000 CNY (AOR $=1.40,95 \% \mathrm{CI}=1.01-2.17$ ), and inpatients $(\mathrm{AOR}=1.46,95 \% \mathrm{CI}=1.01-2.13)$ scored $1-5$ points. In addition, a higher proportion of patients with the highest FPMI $>7,000 \mathrm{CNY}$ showed the lowest satisfaction (AOR $=0.43,95 \% \mathrm{CI}=0.20-0.92$ ) (Table 2).

On the other hand, in terms of the analysis for the highest score group, both univariate logistic regression model and multivariable logistic regression models demonstrated that inpatients were more satisfied with the received medical 
service $(\mathrm{COR}=0.68,95 \% \mathrm{CI}=0.51-0.92 ; \mathrm{AOR}=0.70$, $95 \% \mathrm{CI}=0.54-0.97)$ as compared to outpatients. When compared to younger individuals aged $\leq 25$ years, patients aged $46-65$ years $(\mathrm{OR}=1.61,95 \% \mathrm{CI}=1.39-2.98)$ were more satisfied with the received medical service $(\mathrm{COR}=0.54$, $95 \% \mathrm{CI}=0.37-0.79 ; \mathrm{AOR}=0.63,95 \% \mathrm{CI}=0.33-0.98)$. How ever, those with an associate's or bachelor's degree showed a lower proportion of the highest satisfaction $(\mathrm{COR}=2.52$, 95\% CI $=1.65-3.86$; AOR $=2.40,95 \%$ CI $=1.37-4.20$ ). Top earners with an FPMI $>7,000 \mathrm{CNY}$ also showed a lower proportion of the highest satisfaction $(\mathrm{COR}=3.80$, 95\% CI $=1.46-9.87$; AOR $=3.02,95 \% \mathrm{CI}=1.10-8.33$ ) (Table 3).

\section{Discussion}

The present study found that the top four reasons why migrant patients prefer a certain hospital are: high level of medical treatment, good reputation, advanced medical equipment, and recommendation from a friend or family member. The most significant criteria for patients when choosing a hospital were its service and its reputation. The better a facility's service is and the greater its reputation, the more patients were willing to receive medical treatment there. Improvement of the quality of medical service remains the core part of a hospital's development, which may be further facilitated by better medical equipment. ${ }^{35,36}$ Only through expanding a hospital's medical treatment capabilities, can more people actually be cured and be more satisfied with their medical experience, thereby attracting more patients to visit. Managers of medical facilities should also note the importance of increasing their publicity through a rapidly developing media, as well as the necessity of creating a more patient-friendly medical experience, which will lead to more recommendations from patients to potential patients.

Moreover, the results of our study showed that the top four reasons why ecdemic patients were dissatisfied with their experience at a hospital were long waiting times, complicated formalities and paperwork, poor overall service attitude, and provision of unnecessary services. Among these factors, long waiting times is the most significant one; the number of respondents who selected this option exceeds that of respondents who chose the other ones to a very large degree. The significance of this factor may be explained by the fact that ecdemic patients are already burdened with non-medical costs including travel and accommodation during their trip, and long waiting times will increase such costs..$^{4,7,26,37}$ The uneven distribution of health care resources, with the best medical facilities and equipment concentrated in large cities and large hospitals, may be the primary cause for long queues. ${ }^{26}$ Another reason for long waiting times may be that the increased specialization of medical services into professional clinical departments has complicated and elongated the treatment processes. A possible solution to this is the incorporation of Internet technology into medical service. Moreover, studies have shown that job satisfaction of medical staff affects the quality of their service and subsequently patient satisfaction, especially when the staff works under fatigue. ${ }^{38,39}$ Managers of health care facilities should incentivize their employees and improve their working experience through discreet management and the prevention of working overloads. ${ }^{40,41}$

Using the $80 / 20$ rule, we especially examined the highest and lowest $20 \%$ groups of satisfaction scores. Because the distribution of satisfaction scores skewed in a direction such that it was concentrated around 6 and 7 points, we found $20.14 \%$ of the respondents scored 1-5 points (lowest score group), and $29.62 \%$ scored 8 or 9 points (highest score group). We investigated whether there were patterns in the demographic information of respondents in the lowest and highest score groups, such that we may identify population groups that the managers of hospitals should especially focus on.

It was found that patients with an FPMI between 3,001 and 5,000 CNY had a higher degree of satisfaction than those with an income below 3,000 CNY. Patients with an FPMI above 7,000 CNY reported an even lower satisfaction score than the population group with an income below 3,000 $\mathrm{CNY}$. Moreover, female patients and inpatients were more satisfied with their medical experience than male patients and outpatients, respectively. The low degree of satisfaction among low-income patients may be due to the fact that constraints in their financial resources make it difficult to pay high treatment costs. Those with higher income are more likely to be dissatisfied, as they have higher demands for health care. In several previous related studies, researchers have demonstrated that female patients had a lower degree of satisfaction than males. ${ }^{19,21,22,26,42,43}$ This study, however, detected fewer female patients in the lowest satisfaction group, and yet statistically significant differences between male and female groups were also not found in the highest satisfaction group.

Inpatients were more contented with the medical care that they received, partly due to pronounced effects that they experienced during their long-term stay at a hospital, and partly due to the formation of cordial relationships with staff and increased familiarity with the facility. Therefore, hospitals 
should focus on the medical experience of patients with relatively lower and higher income levels. Some practical measures include: simplifying procedures for claiming reimbursements, providing guidance for low-income patients on such formalities, avoiding prescribing unnecessary treatments to decrease their financial burden, and identifying the expectations and demands of patients with higher income in advance. Moreover, the information desk in each hospital should be fully utilized such that the service for patients is proactive rather than passive. Hospitals should provide navigation for patients to receive examinations or treatments and guide them through any complicated procedures.

Finally, the following limitations can be identified in this study. The confounding factors of patient satisfaction are possibly more than those we investigated. Other factors that may be examined include the distance between the hometown and destination location of ecdemic patients, the type of disease, duration of disease, comorbidities, different clinical department in which a patient receives their treatment, and so on. Since the study was based on a strategy of convenience sampling, such a design may be affected to some extent by sampling bias. Thus, data should be weighted using variables related to the population of reference to achieve better representativeness of the population. However, there were no related previous survey experiences with the sampling frame among this population in China, and the general population characteristics remained unknown. Therefore, we did not weight the data in the present study. Furthermore, the geographic scope of the study was limited. Moreover, the biases related to the face-to-face interviews and non-response bias were not assessed, as only those agreeing to participate were included. Thus, application of the findings to other areas throughout China needs to be done with caution.

\section{Conclusion}

This study has clearly shown that the ecdemic patients were more willing to receive the ecdemic medical care in a certain hospital with a high level of medical treatment, good reputation, and advanced medical equipment. Ecdemic patients were mainly dissatisfied with the long waiting times for care, complicated formalities, a poor overall service attitude, and provision of unnecessary services. Fewer female patients, patients with an FPMI between 3,001 and 5,000 CNY, and inpatients were found in the lowest satisfaction group. Fewer patients with an associate's or bachelor's degree, and top earners with an FPMI $>7,000 \mathrm{CNY}$, were detected in highest satisfaction group. Those aged 46-65 years were mainly detected in the highest satisfaction group. The findings from this study suggested that managers of the medical facilities should note the importance of increasing their publicity through a rapidly developing media, as well as the necessity of creating a more patient-friendly medical care experience. Hospitals should also focus on the medical care experience of patients with relatively lower and higher income levels, male ecdemic patients, and ecdemic outpatients. The information desk in the hospital should be fully utilized such that the service for patients is proactive rather than passive. The information desk should provide navigation for patients to receive examinations or treatments and guide them through any complicated procedures. Hospitals and the physicians should actively and truly practice patient-centered care to improve the patients' clinical outcomes, quality of the doctor-patient relationship, and patient satisfaction.

\section{Acknowledgments}

This study was supported by an internal grant from Wuhan University and the Postgraduate Innovation Project (No YC2015-S039). We wish to thank Dr Mingyang Wu from Tongji Medical College, Huazhong University of Science and Technology, and Prof Dr Zhaokang Yuan, Fei Xie, Xiaoqing Jiang, and other graduate students from the Medical School of Nanchang University for their specific contributions in data collection. We also gratefully acknowledge the assistance and cooperation from the related hospitals and the research participants who contributed their time and effort for this study.

\section{Author contributions}

All authors have approved the content of the submitted manuscript. Dr Xiaojun Liu and Prof Zongfu Mao conceived and designed the study; Dr Xiaojun Liu and research team partners from other units collected data; Dr Xiaojun Liu, Hanson Lu, Yanan Wang, Wenjie Wang, Anran Tan, and Zhaoxun Hou contributed to data analysis and wrote the manuscript; Prof Zongfu Mao, Dr Xiaojun Liu, and Hanson Lu revised the manuscript.

\section{Disclosure}

The authors report no conflicts of interest in this work.

\section{References}

1. Anand S, Fan VY, Zhang J, et al. China's human resources for health: quantity, quality, and distribution. Lancet. 2008;372(9651):1774-1781.

2. Hou JL, Wang ZF, Luo YH, Meng QY. Health professional educational system in China from 1998 to 2012: a time-series analysis. Lancet. 2015;386(Oct):S51.

3. Zhang X, Zhao L, Cui Z, Wang Y. Study on equity and efficiency of health resources and services based on key indicators in China. PLoS One. 2015;10(12):e0144809.

4. Chen J. Internal migration and health: re-examining the healthy migrant phenomenon in China. Soc Sci Med. 2011;72(8):1294-1301. 
5. Zhang $X$, Zhou $X$, Huang $X$, et al. The analysis of the disease spectrum in China. Biomed Res Int. 2014;2014:601869.

6. Lam CLK. What are the important health concepts for the Chinese? Qual Life Res. 1998;7(7):620.

7. Fang P, Dong S, Xiao J, Liu C, Feng X, Wang Y. Regional inequality in health and its determinants: evidence from China. Health Policy. 2010;94(1):14-25.

8. Powell-Jackson T, Yip WC, Han W. Realigning demand and supply side incentives to improve primary health care seeking in rural China. Health Econ. 2015;24(6):755-772.

9. National Health and Family Planning Commission of People's Republic of China. Available from: http://www.nhfpc.gov.cn/zhuz/xwfb/201711/ 6a9007b7754a477a8109fd572853b02a.shtml. Accessed February 28, 2018.

10. National Bureau of Statistics of China. Available from: http://www. stats.gov.cn/tjsj/zxfb/201702/t20170228_1467424.html. Accessed February 28, 2018.

11. National Health and Family Planning Commission of People's Republic of China. Available from: http://www.nhfpc.gov.cn/zhuz/mtbd/201709/ 6c8a18d7990b4adcaf05d7c38707e2b7.shtml. Accessed February 28, 2018.

12. National Health and Family Planning Commission of People's Republic of China. Available from: http://www.nhfpc.gov.cn/jws/xnhzcwj/201 708/170add2740ad473b81d45c8af79ca629.shtml. Accessed February 28,2018

13. National Health and Family Planning Commission of People's Republic of China. Available from: http://www.nhfpc.gov.cn/tigs/s9660/201412 09c02e4b429d405fadf798d94c7caa66.shtml. Accessed February 28, 2018.

14. National Health and Family Planning Commission of People's Republic of China. Available from: http://www.nhfpc.gov.cn/jws/xnhydjy/ xnhydjy.shtml. Accessed February 28, 2018.

15. Sitzia J, Wood N. Patient satisfaction: a review of issues and concepts. Soc Sci Med. 1997;45(12):1829-1843.

16. Lyu H, Wick EC, Housman M, Freischlag JA, Makary MA. Patient satisfaction as a possible indicator of quality surgical care. JAMA Surg. 2013;148(4):362-367.

17. Kato K, O’Malley KJ. Relationships between the eligibility process, trust in the U.S. health care system, and patient satisfaction with the Houston Veterans Affairs Medical Center. Mil Med. 2007;172(8):818

18. Goth US, Hammer HL, Claussen B. Utilization of Norway's emergency wards: the second 5 years after the introduction of the patient list system. Int J Environ Res Public Health. 2014;11:3375-3386.

19. Bjertnaes OA, Sjetne IS, Iversen HH. Overall patient satisfaction with hospitals: effects of patient-reported experiences and fulfilment of expectations. BMJ Qual Saf. 2012;21(1):39-46.

20. Tsai TC, Orav EJ, Jha AK. Patient satisfaction and quality of surgical care in US hospitals. Ann Surg. 2015;261(1):2-8.

21. Kleefstra SM, Kool RB, Zandbelt LC, Haes JD. An instrument assessing patient satisfaction with day care in hospitals. BMC Health Serv Res. 2012;12(1):125.

22. Li M, Huang C, Lu X, Chen S, Zhao P, Lu H. Evaluation of medical staff and patient satisfaction of Chinese hospitals and measures for improvement. Biosci Trends. 2015;9(3):182-189.

23. Cano SJ, Hobart JC. The problem with health measurement. Patient Prefer Adherence. 2011;5:279-290.

24. Jin T. A transformative tale of patients and doctors in China. Lancet. 2011;377(9772):1144.

25. Wang G, Xie J, Hu Y. Doctor-outpatient communications in Chinese public hospitals: a cross-sectional survey. Lancet. 2016;388:S38.
26. Pan J, Liu D, Ali S. Patient dissatisfaction in China: what matters. Soc Sci Med. 2015;143:145-153.

27. Lee YY, Lin JL. Do patient autonomy preferences matter? Linking patient-centered care to patient-physician relationships and health outcomes. Soc Sci Med. 2010;71(10):1811-1818.

28. Xie B, Wang M, Feldman R, Zhou L. Internet use frequency and patient-centered care: measuring patient preferences for participation using the health information wants questionnaire. $J$ Med Internet Res. 2013;15(7):e132.

29. Li DR. Improvement and evaluation of patient satisfaction scale in general hospital. Southern Medical University, Guangzhou, China; 2007. Available from: http://kns.cnki.net/KCMS/detail/detail.aspx?dbcode= CMFD\&dbname $=$ CMFD2008\& filename $=2007223146$.nh\&uid $=$ WEE vREcwSIJHSldRa1FhdkJkVWI3Nkp6bjhkeTlrVzlnd11rSUpSRDIrS $\mathrm{T} 0=\$ 9 A 4 \mathrm{hF} \_Y A u v Q 5 o b g V A q N K P C Y c E j K e n s W 4 g g I 8 F m 4 g T k o U-$ KaID8j8gFw!!\&v=MDcyNzViUElSOGVYMUx1eFITN0RoMVQzc VRyV00xRnJDVVJMS2ZZT2RvRnlybVU3L01WMTI3R2JHNkhkRElxWkU=. Accessed July 19, 2018. Chinese.

30. Legidoquigley H, Glinos I, Baeten R, Mckee M. Patient mobility in the European Union. BMJ. 2007;334(7586):188-190.

31. Andritsos DA, Tang CS. Introducing competition in healthcare services: the role of private care and increased patient mobility. Eur J Oper Res. 2014;234(3):898-909.

32. Brekke KR, Levaggi R, Siciliani L, Straume OR. Patient mobility and health care quality when regions and patients differ in income. $J$ Health Econ. 2016;50:372-387.

33. Sun ZQ, Xu YY. Medical Statistics. 3rd ed. Beijing, China: The People's Medical Publishing House; 2010: 508-509.

34. Cuadras CM, Cuadras D, Lahlou Y. Principal directions of the general Pareto distribution with applications. J Stat Plan Infer. 2006;136(8): 2572-2583.

35. Ly DP, Glied SA. Variations in the service quality of medical practices. Am J Manage Care. 2013;19(11):378-385.

36. Tukey MH, Wiener RS. The impact of a medical procedure service on patient safety, procedure quality and resident training opportunities. J Gen Intern Med. 2014;29(3):485-490.

37. Liu Y, Skup M, Lin J, Chao J. Impact of non-medical switching on healthcare costs: a claims database analysis. Value Health. 2015; 18(3):A252.

38. Weng H, Hung C, Liu Y, et al. Associations between emotional intelligence and doctor burnout, job satisfaction and patient satisfaction. Med Educ. 2011;45(8):835-842.

39. Miao Y, Li L, Bian Y. Gender differences in job quality and job satisfaction among doctors in rural western China. BMC Health Serv Res. 2017; 17(1):848.

40. Fu J, Sun W, Wang Y, Yang X, Wang L. Improving job satisfaction of Chinese doctors: the positive effects of perceived organizational support and psychological capital. Public Health. 2013;127(10):946-951.

41. Yu W, Li M, Chen X, et al. Determinants and influencing mechanism of outpatient satisfaction: a survey on tertiary hospitals in the People's Republic of China. Patient Prefer Adherence. 2016;10(1):601-612.

42. Chen H, Li M, Wang J, et al. Factors influencing inpatients' satisfaction with hospitalization service in public hospitals in Shanghai, People's Republic of China. Patient Prefer Adherence. 2016;10(1):469-477.

43. Paul S, Herrmann FR, Haller DM. Is patient satisfaction with organizational aspects of their general practitioner's practice associated with patient and doctor gender? An observational study. BMC Fam Pract. 2016;17(1):120 


\section{Publish your work in this journal}

Patient Preference and Adherence is an international, peer-reviewed, open access journal that focuses on the growing importance of patient preference and adherence throughout the therapeutic continuum. Patient satisfaction, acceptability, quality of life, compliance, persistence and their role in developing new therapeutic modalities and compounds to optimize

clinical outcomes for existing disease states are major areas of interest for the journal. This journal has been accepted for indexing on PubMed Central. The manuscript management system is completely online and includes a very quick and fair peer-review system, which is all easy to use. Visit http://www. dovepress.com/testimonials.php to read real quotes from published authors.

Submit your manuscript here: http://www.dovepress.com/patient-preference-and-adherence-journal 